\title{
Service value of wetland ecosystem in Sanmenxia Reservoir area
}

\author{
Zhao H. ${ }^{1,2}$, Zhang H.-I. ${ }^{1}$, Wang F.-q. ${ }^{1,2,3 *}$, Kang P.-p. ${ }^{1,3}$, and Lü S.-b. ${ }^{1}$ \\ ${ }^{1}$ Institute of Water Resources, North China University of Water Resources and Electric Power, Zhengzhou 450046, China \\ ${ }^{2}$ Collaborative Innovation Center of Water Resources Efficient Utilization and Support Engineering, Zhengzhou 450046, China \\ ${ }^{3}$ Henan Key Laboratory of Water Environment Simulation and Treatment, Zhengzhou 450046, China \\ Received: 01/07/2020, Accepted: 18/08/2020, Available online: 15/10/2020 \\ *to whom all correspondence should be addressed: e-mail: wangfuqiang@ncwu.edu.cn
}

https://doi.org/10.30955/gnj.003367

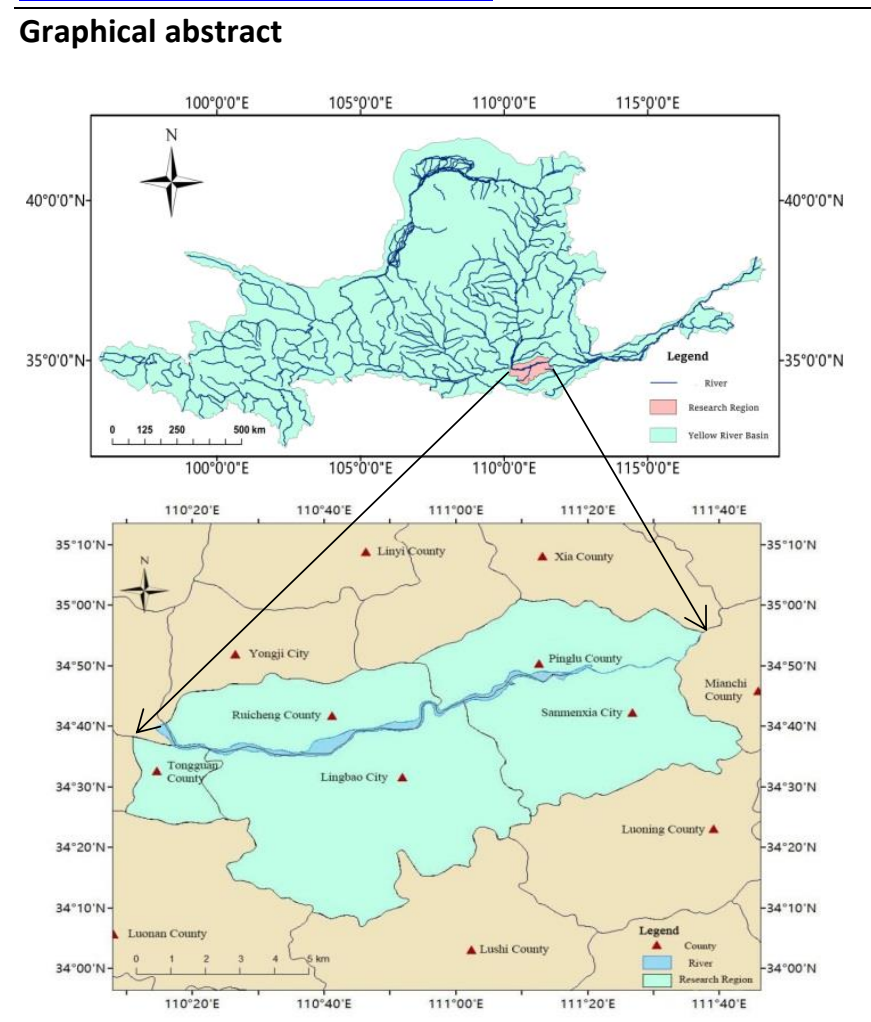

\begin{abstract}
The evaluation of wetland ecosystem service lays the foundation to the wetland protection and exploitation. Evaluating the ecological service of all types of wetlands scientifically and reasonably is critical to improving the quality of ecological environment and securing the regional ecological security. In the middle reaches of the Yellow River, a typical sediment-laden river wetland- Sanmenxia Reservoir area Wetland, is chosen as the research target. Based on the systematic analysis its unique formation process and ecological services, the biological resources are formed, including the value of supply service, regulation service, support service, and cultural service. The value of wetland ecological services was calculated by market value, opportunity cost, shadow engineering and substitution cost methods. The results show that the total value of wetland ecosystem service is worth about 80.86
\end{abstract}

billion yuan, and the dominant ecological services are regulation service and support service with the economic value of $46.49 \%$ and $50.85 \%$ respectively. The evaluation results make people more directly understand the importance of wetland leading ecological service and provide scientific basis for the protection and management of wetland in Sanmenxia Reservoir area.

Keywords: Sanmenxia Reservoir area wetland, wetland protection, wetland exploitation, ecosystem service, value assessment, evaluation method.

\section{Introduction}

As a unique ecosystem for water-land interaction, wetland not only provides food, medicine and other raw materials for production and living of human, but also creates and maintains the life support system of the earth and the environmental conditions necessary for human's survival (Ouyang et al., 1999). Wetland ecosystems play an important role in flood controlling and drought relief, climate regulation, water conservation, flood regulation, land reclamation, biodiversity conservation, tourism and leisure. Therefore, it can bring significant ecological, economic and social benefits to humans (Brouwer et al., 1999). Ecosystem's service refers to the natural environmental conditions and effects that human beings depend on for the ecosystems and in the ecological processes (Lu 2006). The evaluation on the value of ecosystem's service under each type of wetland is conducive to more direct identification of the leading services and ecological value of the wetland ecosystem. The direct monetary value highlights the importance of wetland to regional economic development (Humaira and Saima, 2018; Kong et al., 2015; Sajil Kumar, 2020; Suhaili and Samsudin, 2018; Swodesh and Yuvraj, 2020).

Domestic and foreign scholars have done a lot of researches related to the evaluation on the value of wetland ecosystem services. Costanza (1997) et al. divided the global ecosystem into 16 types and divided the services of each ecosystem into 17 categories, including wetland ecosystems. For the first time, they used the United States, Indonesia and other countries as research targets for calculating the value of wetland ecosystem services, and 
then multiply the total area of global wetlands to estimate the total value of global wetland ecosystem services; Zorrilla-Miras et al. (2014) conducted research and analysis on the impact of land use on the wetland in the Doniana wetland in Spain. According to the results, land use change is the key to the loss of ecosystem service value; Xin et al. (2002) evaluate the service of wetland ecosystem in Panjin District of Liaohe Delta based on the method of GPS, field visit investigation, environmental economics, resource economics, fuzzy mathematics and other research methods. Hence, they obtained the service value of wetland ecosystem in this area is worthy of 6.213 billion yuan; Cui et al. (2016) divided the Zhalong wetland ecosystem services into two parts, the final service and the intermediate service. The value of the final service is regarded as the total value of the wetland ecosystem service. In addition, different evaluation methods, such as the market value method, the shadow price method and the travel expense method, are used. Ecological values are assessed in the form of monetization. The results show that, in 2011, the total value of Zhalong wetland ecosystem services was 67.94 billion yuan, and the intermediate service value was 47.15 billion yuan (Faiza et al., 2018; Fikriah et al., 2019; Md. Nazmul and Bo-Ching, 2019; Okoli et al., 2018).

In this study, the research target was the typical multisediment river wetland-Sanmenxia Reservoir wetland in the middle reaches of the Yellow River. Based on the unique formation process and evolution law of the wetland in the Reservoir area, 10 representative ecological indicators and 2 unique ecological indicators (power generation and sediment transport capacity) were selected. A combination of environmental economics, resource economics and ecological economics (Xea et al., 2007) are adopted for quantitative assessment of the four major services of the wetlands in the Reservoir area. The research results will help people to more directly recognize the importance of the wetland ecosystem's service in the Sanmenxia Reservoir area and provide a theoretical basis for the protection and management of wetland ecosystems and rational development and utilization. It has important scientific significance and practical value.

\section{Overview of the study area}

Based on the Yellow River's characteristics of a large amount of sand and mud, the Sanmenxia Reservoir Wetland (Tongguan-Sanmenxia) in the middle reaches of the Yellow River was selected as the study area (Figure 1). Sanmenxia Reservoir is located at the junction of Sanmenxia City, Henan Province and Pinglu County, Shanxi Province. It is between $108^{\circ} 45^{\prime}-111^{\circ} 20^{\prime}$ east longitude and $340^{\circ} 21^{\prime}-35^{\circ} 50^{\prime}$ north latitude. It is the first comprehensive water conservancy and hydropower project for flood control, anti-flooding, water supply, irrigation and power generation on the mainstream of the Yellow River. The controlled drainage area is $688,000 \mathrm{~km}^{2}$, accounting for 91.5\% of the area of the Yellow River Basin (Cheng et al., 1999). In the process of using the Sanmenxia Water Control Project for more than 50 years, the Reservoir area has formed a relatively stable ecological system. The most representative is the wetland ecosystem, which is the winter habitats of many rare waterfowls (Yang et al., 2014). As the wetland in the Reservoir area is formed under effects of the special water and sand conditions in the middle reaches of the Yellow River and the different operating water levels in the Sanmenxia Water Control Project, the wetland types are rich and diverse, including river wetlands, beach wetlands, lakes and Reservoir wetlands, and marsh wetlands (Zhou et al., 2015). In addition, with the change of Reservoir operation mode, the area of various types of wetlands also changed significantly.

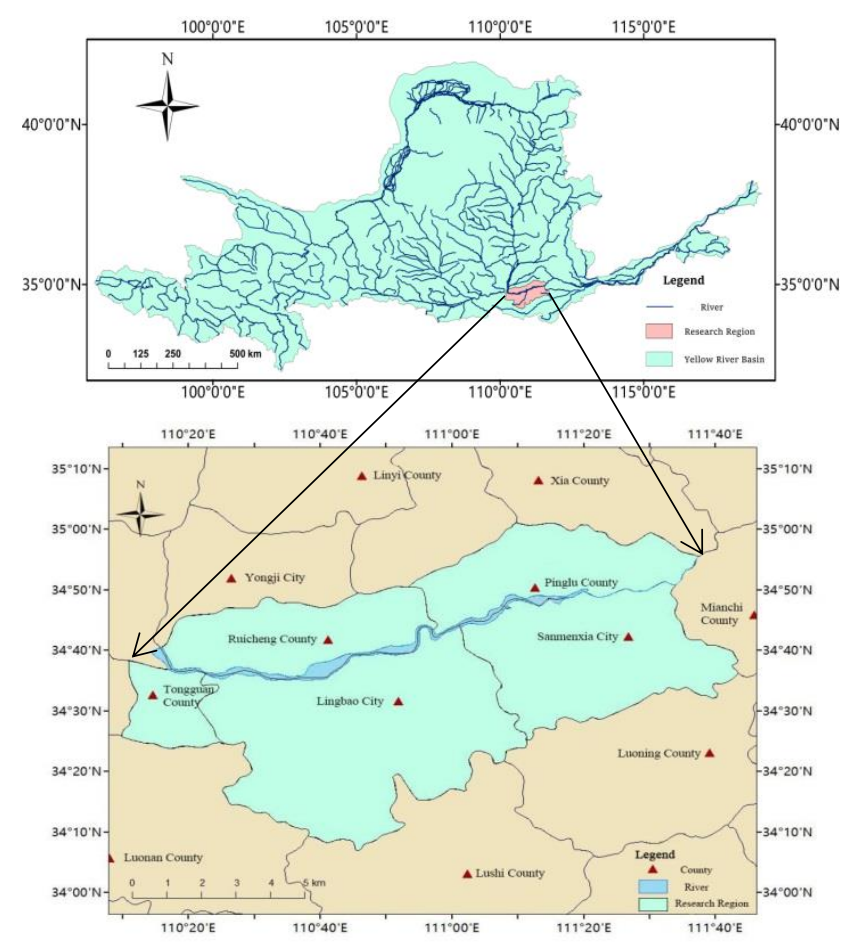

Figure 1. Schematic diagram of wetland research area in Sanmenxia Reservoir

\section{Research method}

\subsection{Data source and method}

\subsubsection{Data sources}

The various parameters cited in the calculation are originated from the observation data of the Sanmenxia Reservoir Wetland Hydrological Observatory (Tongguan Station and Sanmenxia Station), the meteorological data of the China Meteorological Network (Boyd et al., 2019), the experimental data of the field survey and related departments. The obtained data is interpreted and processed by software such as ENVI and GIS, and the processing results are statistically analyzed.

\subsubsection{Evaluation method}

Fu Jiaoyan et al. (2007) combined the research results of ecological and environmental economics and divided the evaluation methods of wetland ecosystem service into income market evaluation, damaged market evaluation, 
inferential market evaluation and hypothetical market evaluation methods.

1. The income market assessment method means that the value generated by the wetland can be obtained through direct or indirect market transactions, including market value method, production service method, opportunity cost method and shadow engineering method;

2. The damaged market assessment is to obtain the indirect value by estimating the compensation cost due to the damage of the wetland, including the change of vitality method, the human capital law, the recovery cost method and the protection cost method;

3. Inferring the market assessment is to estimate the value of people's environmental preferences by observing people's market behavior, including expense expenditure method, travel expense method, hedonic value method, etc.;

4. Assume that market assessment is based on the lack of real market data or even indirect observation of people's market behavior (MekaMechenko et al., 2017). It is necessary to establish a hypothetical market and conduct an assessment by investigating people's wishes to determine certain non-market goods or services. Value mainly includes the alternative cost method and the contingent valuation method.
Based on a comprehensive analysis of the ecological services provided by the wetland ecosystem in the Sanmenxia Reservoir area, this study selects the market value method (We, 1977), the carbon tax method (Zhou et al., 2011), the opportunity cost method (Ding et al., 2015), the shadow engineering method (Xea et al., 2007), and the replacement. The cost method (Yan et al., 2000), the outcome parameter method (Su et al., 2012) and the travel expense method (Sutton et al., 2002) and other commonly used value assessment methods of wetland ecosystem services at home and abroad, to assess the ecological services' value of the wetland in the Reservoir area.

\subsection{Establishment of evaluation index system}

According to the principle of ecological and ecosystem services, the characteristics of wetland ecosystem in Sanmenxia Reservoir area, and the characteristics of wetland ecosystem types, structures and ecological processes in the Reservoir area (Woodward et al., 2001), the wetland ecosystem services of Sanmenxia Reservoir area can be divided into supply, adjustment, support, and cultural services. Then, from the unique geographical location and formation conditions of the wetland in the Reservoir area (Fidan et al., 2016), 12 ecological indicators with representative and unique characteristics were selected, and the evaluation index system of wetland ecosystem service value in Sanmenxia Reservoir Area was built (Table 1).

Table 1. Evaluation index system of wetland ecosystem services in Sanmenxia Reservoir Area

\begin{tabular}{ccc}
\hline Service classification & Evaluation index & Evaluation method \\
\cline { 2 - 3 } Supply service & Biological resources & Market value method \\
\cline { 2 - 3 } & Water resources & Market value method \\
\cline { 2 - 3 } & Power generation & Market value method \\
\cline { 2 - 3 } Adjustment service & Atmospheric regulation & Carbon Tax Law \\
\cline { 2 - 3 } & Climate regulation & Mpportunity cost method \\
\cline { 2 - 3 } & Sand transport capacity & Market value method \\
\cline { 2 - 3 } & Regulate flood & Shadow engineering \\
\cline { 2 - 3 } & Purify water quality & Alternative cost method \\
\cline { 2 - 3 } & Biodiversity conservation & Result reference method \\
\hline \multirow{2}{*}{ Sultural service } & Maintain ecosystem integrity & Market value method \\
\cline { 2 - 3 } & Teaching and research & Result reference method \\
\cline { 2 - 3 }
\end{tabular}

\section{Value assessment on the ecosystem service}

\subsection{Value assessment on the supply service}

\subsubsection{Biological resources}

The biological resources provided by the Sanmenxia Reservoir Wetland ecosystem are mainly aquatic products and plant resources. The assessment formula of the biological resource value is:

$$
V_{1}=\sum T_{i} \cdot P_{i}
$$

In the formula: $V_{1}$ is the total value of biological resources, unit: yuan; $T_{i}$ is the output of the main biological resources of the wetland in the Reservoir area, unit: $t \cdot a^{-1} ; P i$ is the market unit price of the corresponding biological resources, unit: yuan.

According to the investigation and evaluation on aquatic resources in the Yellow River wetland, the annual output of wetland aquatic products in the Sanmenxia Reservoir area is about 76,000 tons, and the annual output of reeds, about 5,700 tons. The average price of aquatic products monitored by the Ministry of Agriculture was selected as the price index (Nowak et al., 2017). The average value of aquatic products was 16.33 yuan $/ \mathrm{kg}$. Based on the market price difference between general reed and fine reed in the 
market, the average market price range of the two was estimated to be 0.41 yuan $/ \mathrm{kg}$. Finally, the total value of the wetland biological resources in the Sanmenxia Reservoir area was $1,243.3$ million yuan.

\subsubsection{Water resources}

Sanmenxia Water Conservancy Project is a comprehensive water conservancy project in combination of power generation, irrigation and flood control. It provides abundant power for Henan, Hebei and Shanxi provinces, irrigation water source for Henan province, and plays a major role in flood control in Henan and Shandong provinces (Lee and van der Heijden, 2019). At the same time, Sanmenxia Reservoir is also the main source of water supply for more than 300,000 people. The assessment formula of water resource value is as follows:

$$
V_{2}=\sum Q_{i} \cdot P_{i}
$$

In the formula: $V_{2}$ refers to the total value of water resources, unit: yuan; $Q_{i}$ means the water consumption of each industry, unit: $t \cdot m^{-3} ; P i$ is the price of water unit in the corresponding industry, unit: yuan $\cdot \mathrm{m}^{-3}$.

The annual average water consumption of the Sanmenxia Reservoir is 450 million $\mathrm{m}^{3}$, among which agricultural water supply and the industrial water supply accounts for $89 \%$ $\left(400.5\right.$ million $\left.\mathrm{m}^{3}\right)$ and $6 \%\left(27\right.$ million $\left.\mathrm{m}^{3}\right)$ respectively, and the urban life takes $4 \%\left(18\right.$ million $\left.\mathrm{m}^{3}\right)$. In Sanmenxia City, the residential water is $1.3 \mathrm{yuan} / \mathrm{m}^{3}$, industrial water is 2.1 yuan $/ \mathrm{m}^{3}$, and agricultural water is 0.32 yuan $/ \mathrm{m}^{3}$. Finally, it is calculated that the supply value of wetland water resources in Sanmenxia Reservoir Area is 208 million yuan.

\subsubsection{Power generation}

The Sanmenxia Water Control Project is the first large-scale water conservancy hub built on the main stream of the Yellow River. It has comprehensive utilization benefits such as power generation, flood control and irrigation. The power generation value assessment formula is shown as follows:

$$
V_{3}=E \cdot R \cdot P
$$

In the formula: $V_{3}$ is the total value of power generation, unit: yuan; $E$ is the average annual power generation, unit: $K w \cdot h ; R$ is the average line loss rate of the grid enterprise, unit: $\% ; P$ refers to the average power price of national power generation enterprises, unit: yuan $\cdot(\mathrm{Kw} \cdot \mathrm{h})^{-1}$.

According to the statistics, after three renovations, the existing installed capacity of the Sanmenxia Hydropower Station reaches $400 \mathrm{MW}$, and the average annual power generation is 1.317 billion $\mathrm{kw} \cdot \mathrm{h}$ (Cheng et al., 2019). The average annual line loss rate of national grid enterprises in 2013-2017 accounts for $6.45 \%$, and the average on-grid price of power generation enterprises in China is 0.39 yuan/Kw.h. In summary, the total value of the wetland power generation in the Sanmenxia Reservoir area is 481 million yuan.

\subsection{Value assessment on adjustment service}

\subsubsection{Atmospheric regulation}

The wetland fixes the $\mathrm{CO}_{2}$ in the atmosphere, releases $\mathrm{O}_{2}$ into the atmosphere through the photosynthesis of large areas of the reed plants and other aquatic plants, hence regulating the atmosphere to reach the dynamic balance of $\mathrm{CO}_{2}$ and $\mathrm{O}_{2}$ in the atmosphere. The formula for evaluating the value of atmospheric regulation is:

$$
\begin{aligned}
& M_{1}=1.63 \cdot T \\
& M_{2}=1.2 \cdot T \\
& V_{4}=\sum M_{i} \cdot P_{i}
\end{aligned}
$$

In the formula: $V_{4}$ is the total value of atmospheric regulation, unit: yuan; $M_{1}$ is the annual fixed $\mathrm{CO}_{2}$ amount, unit: $t \cdot a^{-1} ; M_{2}$ is the annual release of $\mathrm{O}_{2} ; T$ is the annual plant production, unit: $t \cdot a^{-1}$; and $P_{i}$ is the price of carbon fixation, unit: yuan $\cdot \mathrm{t}^{-1}$.

According to the current international standard for carbon tax rate and China's reality, the research takes China's afforestation cost of 250 yuan/t and average of 770 yuan/t based on the international carbon tax standard of 150 dollars/t as the carbon tax standards, the amount of $\mathrm{CO}_{2}$ absorbed Sanmenxia Reservoir area wetland plants is 9291 $t$, and the value of $\mathrm{CO}_{2}$ absorbed by wetland plants in Sanmenxia Reservoir area is calculated to be $715 \times 10^{4}$ yuan (Abdin et al., 2018). The value of $\mathrm{O}_{2}$ released by wetland plants in Sanmenxia Reservoir area is calculated by using the industrial manufacturing cost of oxygen as the shadow price. As the industrial oxygen cost is 400 yuan/t, the value of annual release of $\mathrm{O}_{2}$ is calculated to be $274 \times 10^{4}$ yuan. Finally, the total value of the atmospheric regulation of the Sanmenxia Reservoir area is calculated to be 0.099 billion yuan.

\subsubsection{Climate regulation}

Wetland water is continuously released to the atmosphere through plant transpiration and water evaporation, thereby increasing air humidity and reducing air temperature to achieve climate regulation. The assessment formula for climate adjustment value is:

$$
V_{5}=\frac{E_{z}+E_{\mathrm{s}}}{2} \cdot A \cdot P
$$

In the formula: $V_{5}$ represents the total value of atmospheric regulation, unit: yuan; $E z$ refers to the plant evapotranspiration in the Reservoir area, unit: $\mathrm{mm}$; $E s$ is the water surface evaporation of the wetland in the Reservoir area, unit: $\mathrm{mm}$; $A$ means the water surface area of the wetland in the Reservoir area, unit : $\mathrm{km}^{2} ; P$ is the unit price of water resources.

The Sanmenxia Reservoir area owns a large number of reeds in a wide distribution area. They are the main players in the transpiration of plants and the typical dominant plant species in the Reservoir area. In the study, the evapotranspiration of reeds is used as the transpiration of plants in the Reservoir area. The average annual evapotranspiration of the Sanmenxia Reservoir area is $1,056.59 \mathrm{~mm}$; the evaporation of the wetland surface in the Reservoir area is the main source of water evaporation (Ingarao et al., 2018). According to the observation data on the station in the study area, the average annual evaporation of the wetland surface in the Reservoir area is 
$1,732.85 \mathrm{~mm}$. Based on ENVI software, the average surface area of the Sanmenxia Reservoir Wetland is interpreted to be $85 \mathrm{~km}^{2}$; according to the water supply authority of Sanmenxia City, the water resource price is 1.3 yuan $/ \mathrm{m}^{3}$. Therefore, the total value of the climate regulation of the Sanmenxia Reservoir area is calculated to be 155 million yuan.

\subsubsection{Sand transport capacity}

With the people's improving understanding of social environment and water and sand resources and the development of economy and society, sediment resources are gradually recognized and widely used in production and practice (Khoo et al., 2019). As an inexhaustible resource, sediment has great potential for development and utilization. The formula for evaluating the value of sediment transport capacity is shown as:

$$
V_{6}=S \cdot P
$$

In the formula: $V_{6}$ is the total value of sediment transport capacity, unit: yuan; $S$ is the average annual sediment transport, unit: $\mathrm{t} \cdot \mathrm{a}^{-1} ; P$ means the price of market neutral sediment, unit: yuan $\cdot \mathrm{m}^{-3}$.

The average annual sediment transport volume of mainstream flow control hydrological station (Tongguan Station) on the Yellow River is $\mathbf{2 5 6}$ million tons. At present, the price of medium-sized sediment in the domestic building materials market generally ranges from 100-160 yuan $/ \mathrm{m}^{3}$, so the average value of 130 yuan $/ \mathrm{m}^{3}$ is taken. Therefore, the value of sediment transport capacity of the Sanmenxia Reservoir Wetland is 33.28 billion yuan.

\subsubsection{Regulating flood}

The formation of Sanmenxia Reservoir area wetland is closely related to the construction of the Sanmenxia water conservancy project. The formation of wetlands mainly depends on the application of water conservancy projects. The determination of the value of flood regulation in the Reservoir area also depends on the engineering data of the Sanmenxia Water Control Project. The formula for evaluating the value of flood regulation is:

$$
V_{7}=C \cdot P
$$

In the formula: $V_{7}$ is the value of flood regulation, unit: yuan; $C$ is the flood control capacity, unit: $\mathrm{m}^{3} ; P$ is the price of building Reservoir capacity, unit: yuan $\cdot \mathrm{m}^{-3}$.

The Sanmenxia Water Conservancy Project is located in the lower reaches of the middle reaches of the Yellow River. The controlled drainage area accounts for $91.5 \%$ of the total drainage area of the Yellow River and $89 \%$ of the inflow. It plays a huge role in flood control and regulation. After the reconstruction of the Sanmenxia Water Control Project, the highest flood control water level is $335 \mathrm{~m}$, the flood control capacity is about 6 billion $\mathrm{m}^{3}$, and the cost of constructing water conservancy facilities is 0.67 yuan. Therefore, the value of the flood regulation in the Sanmenxia Reservoir area is calculated to be 4.02 billion yuan.

\subsubsection{Water purification}

The herbaceous plants in the wetlands of Sanmen Reservoir area are lush, such as reeds, cattails, alfalfa and lotus, which can effectively purify the water of the reservoir. The sewage in the reservoir is mainly industrial wastewater and domestic sewage. There are more ammonium nitrogen and dissolved potassium phosphate in the water. These two inorganic nutrients can be easily absorbed by soil particles. The formula for evaluating the value of purified water is:

$$
V_{8}=W \cdot P
$$

In the formula: $V_{8}$ is the value of water purification in wetland, unit: yuan; $W$ is the amount of waste water discharged by the unit, unit: $t$; $P$ is the operating cost of the sewage treatment plant, unit: yuan $\cdot \mathrm{t}^{-1}$.

At present, the discharge of waste water from the Yellow River is 4.337 billion tons. The sewage discharge in the study area is $2.1 \%$ of the discharge of waste water from the Yellow River basin, or 91.1 million tons. At present, the operating cost for China's sewage treatment plant is between 0.51-3.01 yuan/t the average operating cost is 1.38 yuan/t (the average construction cost is 0.37 yuan/ $t$, the average sewage operating cost is 0.81 yuan/t, and the average treatment cost of sludge is 0.20 yuan/t) to evaluate the value of water purification in the Sanmenxia Reservoir area. Hence, the value of the purified water quality of the Sanmenxia Reservoir area is calculated to be 126 million yuan.

\subsection{Value assessment on support services}

\subsubsection{Biodiversity conservation}

The Sanmenxia Reservoir area is rich in wetland species and plays an important role in maintaining biological habitats and biodiversity. The formula for assessing the value of biodiversity conservation is:

$$
V_{9}=H \cdot P
$$

In the formula: $V_{9}$ is the conservation value of wetland biodiversity, unit: yuan; $H$ means the wetland area of Sanmenxia Reservoir area, unit: $\mathrm{hm}^{2} ; P$ refers to the biological habitat value of wetland ecosystem per unit area, unit: yuan $\cdot \mathrm{hm}^{-2}$.

The wetlands in the Reservoir area are abundant in animal and plant resources and are the winter habitats of many rare waterfowls. In this section, the bio-habitat value of the wetland ecosystem in China is estimated to be 2,203 yuan $/ \mathrm{hm}^{2}$ and the natural habitat value of the wetland ecosystem evaluated by Costanza et al. is US $\$ 304 / \mathrm{hm}^{2}$ (equivalent to RMB 2087.3 yuan $/ \mathrm{hm}^{2}$ ). The value is $2,145.2$ yuan $/ \mathrm{hm}^{2}$. The wetland area of the Reservoir area is 18,450 $\mathrm{hm}^{2}$. Hence, it is calculated that the conservation value of wetland biodiversity in Sanmenxia Reservoir Area is 0.4 billion yuan.

\subsubsection{Ecosystem integrity}

The Sanmenxia wetland ecosystem ensures the energy flow between the species within the system, the material circulation between the biomes and the environment, and maintains the normal process of species survival and 
evolution. The ecosystem integrity value assessment formula is:

$$
V_{10}=Q_{m} \cdot P
$$

In the formula: $V_{10}$ represents the integrity value of wetland ecosystem, unit: yuan; $Q_{m}$ is ecological water demand, unit: $\mathrm{m}^{3} ; P$ means the unit price of water resources, unit: yuan $\cdot \mathrm{m}^{-3}$.

According to the literature, the minimum ecological water requirement of the Sanmenxia Reservoir Wetland is 16.835 billion $\mathrm{m}^{3}$, the suitable ecological water requirement, 17.869 billion $\mathrm{m}^{3}$, and the ideal ecological water requirement, 20.211 billion $\mathrm{m}^{3}$. In order to maintain the integrity of the wetland ecosystem in the Sanmenxia Reservoir area and ensure the normal ecological services, this study uses a minimum water requirement of 16.835 billion $\mathrm{m}^{3}$ and a water supply price of 1.3 yuan $/ \mathrm{m}^{3}$ provided by the Sanmenxia water supply authority. Therefore, the value of the wetland ecosystem integrity in the Sanmenxia Reservoir area is 21.86 billion yuan.

\subsection{Value assessment on cultural service}

\subsubsection{Academic research}

The value on education-oriented and scientific research provided by the Sanmenxia Reservoir area wetland is evaluated by the alternative cost method. The average value of education and scientific research value per unit area of wetland ecosystem is adopted to calculate the value of scientific and academic research in the Sanmenxia Reservoir area. The evaluation formula for academic and research value is:

$$
V_{11}=H \cdot P
$$

In the formula: $V_{11}$ represents the academic and research value, unit: yuan; $H$ is the wetland area of Sanmenxia Reservoir, unit: $\mathrm{hm}^{2} ; P$ refers to the educational value of wetland per unit area, unit: yuan $\cdot \mathrm{hm}^{-2}$.

According to the average scientific research value of the wetland ecosystem per unit area in China and the average value of 3146.3 yuan $/ \mathrm{hm}^{2}$ for the evaluation of the global wetland ecosystem scientific research education by Costanza et al., the educational research value of the wetland in the study area. The wetland area of the Sanmenxia Reservoir area is $18,450 \mathrm{hm}^{2}$. Finally, the academic and research value of the wetland in Sanmenxia Reservoir Area is calculated to be 58 million yuan.

\subsubsection{Leisure travel}

The wetlands of the Sanmenxia Reservoir area enjoy beautiful scenery, rare birds and colorful humanities landscapes. The natural resources and eco-tourism resources are combined to form a unique wetland natural human landscape with high tourism value. The value of leisure travel is calculated by using the travel cost method:

$$
V_{12}=F_{1}+F_{2}+F_{3}
$$

In the formula: $V_{12}$ is the total value of tourism, unit: yuan $\cdot a^{-1} ; F_{1}$ is the direct income of tourism (including tickets, hotel income, tourism goods expenditure and parking fee s), unit: yuan $a^{-1} ; F_{2}$ is travel expenses (transportation and accommodation costs), Unit: yuan $\cdot \mathrm{a}^{-1}$; $F_{3}$ is the travel time value (hourly wage standard $x$ total travel hours $\times 40 \%$ ).

According to the survey, the Sanmenxia Wetland receives 130,000 visitors a year, with an income of 113 million yuan, an average travel cost of 200 yuan, an average travel time of 1.5 days, and an average daily wage of 300 yuan. Therefore, the value of leisure tourism in the Sanmenxia Reservoir area is calculated to be 162 million yuan/year.

\subsection{Discussion and analysis}

Table 2 shows the services of different ecosystems in the Sanmenxia Reservoir area and their corresponding value. As the individual ecosystem services are based on the differences between the evaluation methods and data sources, there is a possibility that the evaluation results are lower than the actual ones. Through the evaluation of the 12 ecological indicators of the 4 major services of the Sanmenxia Reservoir area, the total value of the wetland ecosystem service in the reservoir area is 80.86 billion yuan, of which the proportion of the regulatory service value accounts for $46.49 \%$ among the four ecosystem services. The support service accounts for $50.85 \%$, and the combined proportion of the two accounts for $97.34 \%$. The ecological value of the two services accounts for almost all the ecological services of the wetland in the reservoir area. It can be seen from Table 2 that the main services of the Sanmenxia Reservoir Wetland are to maintain the integrity of the ecosystem > sediment transport capacity $>$ flood regulation > biological resources $>$ power generation $>$ water resources $>$ leisure tourism $>$ climate regulation $>$ water purification $>$ academic and research $>$ biodiversity conservation $>$ atmospheric regulation. It can be seen that the main services of the Sanmenxia Reservoir Wetland are to maintain ecosystem integrity, sediment transport capacity, and flood regulation, which are worth 41.077 billion yuan, 33.28 billion yuan, and 4.02 billion yuan respectively.

\section{Conclusion}

The Sanmenxia Reservoir Wetland has an important ecological role, so the evaluation of the ecosystem service lays the foundation for the wetland protection and development and utilization of the Sanmenxia Reservoir area, and for ensuring the sustainable use of the wetland resources in the Sanmenxia Reservoir area. The study concluded that the total value of wetland ecosystem services in the Sanmenxia Reservoir area is 80.86 billion yuan, of which the service of the four ecosystem services accounts for $2.39 \%$ of the total value, the regulation service accounts for $46.49 \%$, the support service accounts for $50.85 \%$, and the cultural service accounts for $0.27 \%$. The evaluation results show that the value of the wetland ecosystem service in the Sanmenxia Reservoir area is very considerable, and it also has significant ecological benefits and direct economic benefits. In particular, core services, such as maintaining ecosystem integrity, sediment transport capacity, and flood regulation are potential and 
intangible services that are easily neglected. If we only pay attention to the obvious economic value, it will inevitably result in the loss of the service value of the ecosystem and the destruction of the ecosystem. In recent years, with the rapid development of the economy, the urban development and construction process has accelerated. The wetland resources in the Sanmenxia Reservoir area are also disrupted by various factors, such as river pollution, destruction of animals and plants, and large-scale tidal flat wetlands being occupied as farmland. This directly leads to the decline of wetland ecological services and value reduction.

The Sanmenxia Reservoir area wetland ecosystem provides many ecological services. In this study, only 12 representative and unique ecological indicators were selected, and the value of the wetland ecosystem service in the Reservoir area was estimated. However, due to the lack of basic data and the lack of evaluation methods, the evaluation results vary. For example, in this study, the wetland tourism resources in Sanmenxia Reservoir area are unevenly distributed in this area. The value of wetland tourism service value in the Reservoir area is calculated by using the value of wetland leisure tourism per unit area. It is impossible to accurately assess the value of tourism services. In addition, in the assessment of biodiversity

Table 2. The value of wetland ecosystem service in Sanmenxia Reservoir Area

\begin{tabular}{|c|c|c|c|c|}
\hline Services & \multicolumn{2}{|c|}{ Value (billion) } & \multicolumn{2}{|c|}{ Proportion (\%) } \\
\hline \multirow{3}{*}{ Supply service } & Biological resources & 12.433 & 1.54 & \multirow{3}{*}{2.39} \\
\hline & Water resources & 2.08 & 0.26 & \\
\hline & Power generation & 4.81 & 0.59 & \\
\hline \multirow{5}{*}{ Adjustment service } & Atmospheric regulation & 0.099 & 0.01 & \multirow{5}{*}{46.49} \\
\hline & Climate regulation & 1.55 & 0.19 & \\
\hline & Sand transport capacity & 332.8 & 41.16 & \\
\hline & Regulate flood & 40.2 & 4.97 & \\
\hline & Purify water quality & 1.26 & 0.16 & \\
\hline \multirow{2}{*}{ Support service } & Biodiversity conservation & 0.4 & 0.05 & \multirow{2}{*}{50.85} \\
\hline & Maintain ecosystem integrity & 410.77 & 50.80 & \\
\hline \multirow{2}{*}{ Cultural service } & Academic and research & 0.58 & 0.07 & \multirow{2}{*}{0.27} \\
\hline & Leisure Travel & 1.62 & 0.20 & \\
\hline Total & 808.6 & 100 & 100 & \\
\hline
\end{tabular}

\section{Acknowledgements}

The work was financially supported by National Natural Science Foundation of People's Republic of China (51709111, 51879106, 51709112), the National Key Research and Development Program of China (2016YFC0401401), the Outstanding Youth in Science and Technology Innovation Talents of Henan province (185100510014), and the Science and Technology Innovation Team in Universities of Henan Province (20IRTSTHN010). In addition, the authors would like to express their sincere gratitude to the anonymous reviewers for their constructive comments and useful suggestions that helped us improve our thesis.

\section{References}

Abdin G.C. and Noussan M. (2018), Electricity Storage Compared to Net Metering in Residential PV Applications, Journal of Cleaner Production, 176: 175-186.

Boyd A.D., Liu J. and Hmielowski J.D. (2019), Public support for energy portfolios in Canada: How information about cost and conservation and cultural research valued, the research methods and application parameters of Costanza commonly used in domestic wetland evaluation are adopted, which is difficult to directly reflect the ecological service value provided by the wetland ecosystem in the targeted area. In the future research, we should focus on the structural composition, specific services and changing processes of the wetland ecosystem in the Reservoir area, and explore the complex relationship between the ecosystem system and the economic system, in order to fully and accurately reflect the value of various ecological services provided by the Sanmenxia wetland ecosystem.

Since different types of wetland ecosystem services provide different services, appropriate evaluation methods should be adopted. As the research on the evaluation of wetland ecosystem services is gradually deepened, a more complete evaluation system and calculation method will be applied. It is hoped that policy makers and administration departments at all levels will use the data and analysis on this research in wetland protection and management to formulate and implement reasonable wetland protection policies and measures to promote the healthy and sustainable development of the wetland ecosystem throughout the Reservoir area. 
Ding D.J., Li M., Liao B.W., et al. (2015), Evaluation of Economic Value of Coastal Natural Wetland Ecosystem Services of Hainan Province, Ecology and Environmental Sciences, 24(9): 1472-1477.

Faiza J., Rizwan A. and Muhammad A.A. (2018), Design, Fabrication and Evaluation of Rotary Hot-Air Dryer for The Value Addition of Fruit Waste, Earth Sciences Pakistan, 2(2), 07-11.

Fidan E.C. and Sirin U. (2016), The Changes Related with Altitudinal Gradient and Seasonal Variation in the Species Composition of Carabidae (Coleoptera) in Turkmen Mountain (Eskisehir, Turkey), EKOLOJI, 25(98): 17-24.

Fikriah F., Kamaruzzaman Y., Mohd F.M. and Azman A. (2019), Assessment of Trace Metals Using Chemometric Analysis in Kuantan River, East Coast Malaysia, Journal Clean WAS, 3(2), 1-4.

Fu J.Y. and Ding Zh.H. (2007), Research progress on ecosystem service and its valuation, Chinese Journal of Applied Ecology, 18(3): 681-686.

Humaira G. and Saima N. (2018), Heavy Metal Uptake from Contaminated Water Using Carbon Nanotubes: A Review. Environmental Contaminants Reviews, 1(2), 4-8.

Ingarao G., Priarone P.C., Deng Y. and Paraskevas D. (2018), Environmental Modelling of Aluminium Based Components Manufacturing Routes: Additive Manufacturing Versus Machining Versus Forming, Journal of Cleaner Production, 176: 261-275.

Khoo S.C., Phang X.Y., Ng C.M., Lim K.L., Lam S.S. and Ma N.L. (2019), Recent technologies for treatment and recycling of used disposable baby diapers, Process Safety and Environmental Protection, 123(B): 116-129.

Kong D.S. and Zhang H. (2015), Economic value of wetland ecosystem services in the Heie National Nature Reserve of Zhangye. Acta Ecologica Sinica, 35(4): 972-983.

Lee T. and van der Heijden J. (2019), Does the knowledge economy advance the green economy? An evaluation of green jobs in the 100 largest metropolitan regions in the United States, Energy \& Environment, 30(1): 141-155.

Lu J.J. and Wetland E. (2006). Beijing: Higher Education Press, 2006, 207-215.

Md. Nazmul A. and Bo-Ching C. (2019), Sustainable Water Treatment Management, Water Conservation and Management, 3(1), 11-13.

Meka-Mechenko T.V., Sagiyev Z.A., Begimbayeva E.Z., Nekrassova L.E., Kovaleva G.G., Izbanova U.A., Lukhnova L.Y., Kunitsa T.K. and Umarova S.K. (2017), Rapid Antimicrobial Susceptibility Testing of Yersinia Pestis Strains from Kazakhstan Plague Foci, EKOLOJI, 26(102): 5-11.

Nowak S. and Myslajek R.W. (2017), Response of the Wolf (Canis Lupus Linnaeus, 1758) Population to Various Management Regimes at the Edge of Its Distribution Range in Western Poland, 1951-2012, Applied Ecology and Environmental Research, 15(3): 187-203.

Okoli E.A., Agbasi O.E., Akaolisa C.C.Z. and Inyang N.J. (2018), Seismic Analysis of The Transgressive Systems Tracts (TSTS) Of the Niger Delta, Earth Sciences Malaysia, 2(2), 16-19

Ouyang Z.Y., Wang R.S. and Zhao J.Zh. (1999), Ecosystem services and their economic valuation, Chinese Journal of Applied Ecology, 10(5): 635-640.
Sajil Kumar P.J. (2020), Hydrogeochemical and multivariate statistical appraisal of pollution sources in the groundwater of the lower Bhavani River basin in Tamil Nadu, Geology, Ecology, and Landscapes, 4(1), 40-51

Su S.C., He D.J., Wang R., et al. (2012) Evaluation of Ecosystem Services of the Coastal, Wetland Science \& Management, 8(3): 14-18.

Suhaili M.Z. and Samsudin M.D.M. (2018), Utilization of Wastewater for Corrosion Prevention of Carbon Steel Pipe Using Single Chamber Microbial Fuel Cells, Environment \& Ecosystem Science, 2(2), 47-52.

Sutton P.C.P.D. and Costanza R.C.C.U. (2002), Global Estimate of Market and Non-market Values Derived from Nighttime Satellite Imagery, Land Cover, and Ecosystem Service Valuation, Ecological Economics, (3): 509-527.

Swodesh R. and Yuvraj D. (2020), A Review On Various Management Method Of Rice Blast Disease, Malaysian Journal of Sustainable Agriculture, 4(1), 29-33.

We W. (1977) How Much Are Nature's Services Worth? Science, (4307): 960-964.

Woodward R and Wui Y. (2001), The Economic Value of Wetland Services Ameta-analysis. Ecological Economics, 37(2): 257270.

Xea A.G. and Kytziab T.A.S. (2007), Integrating the Valuation of Ecosystem Services into the Input-Output Economics of an Alpine Region, Ecological Economics, (4): 786-798.

Xea A.G. and Kytziab T.A.S. (2007), Integrating the Valuation of Ecosystem Services into the Input-Output Economics of an Alpine Region, Ecological Economics, (4): 786-798.

Xin W. and Xiao Y.N. (2002), Wetland Ecosystem Service Valuation-A Case Researches on Panjin Area, Acta Ecologica Sinica, 22(08): 1345-1349.

Yan C.G., Zhang M.X. and Wang J.C. (2000), Study on Valuation Indexes and Methods of Wetland Biodiversity in China, Forest Resources Management, 12(1): 41-46.

Yang H., Wang S.Y., Li Z.P., et al. (2014), Relationship Between the Change of Water \& Sediment and Wetland Landscape in Sanmenxia Reservoir Area, Yellow River, 36(7): 73-75.

Zhou B.H., Cao J.J., Zhu C.P., et al. (2011), Valuation of wetland ecosystem services along the Yangtze River in Anqing, Anhui Province, Geographical Research, 30(12): 2296-2304.

Zhou W.B., Li Y.P., Wang S.Y., et al. (2015), Estimation of ecological water demand in Sanmenxia reservoir wetland, South-to-North Water Transfers and Water Science \& Technology, 13(5).

Zorrilla-Miras P., Palomo I., Gómez-Baggethum E., et al. (2014), Effects of Land-see Change on Wetland Ecosystem Services: A Case Study in the Doñana marhes (SW Spain), Landscape \& Urban Planning, 122: 160-174. 